\title{
Ortodoxia y herejía en el hinduismo ${ }^{1}$
}

\section{Orthodoxy and heresy in Hinduism}

\section{LUIS GONZÁLEZ REIMANN*}

Resumen: Se examina el uso de tres términos empleados con frecuencia a lo largo de los siglos en ciertos géneros de literatura de los brahmanes para designar a los herejes. Se trata de las palabras nāstika, asura y pàsaṇda. A fin de ver cómo se emplean en los textos, se revisan algunos ejemplos de narraciones que los utilizan en distintos contextos, en particular en las epopeyas sánscritas y los purānas. Se incluyen, además, algunos ejemplos de su uso por parte de autores budistas.

Palabras clave: $R g$ veda; vedas; hinduismo; epopeyas sánscritas; Mahābhārata.

Abstract: This article studies three commonly used concepts in some genres of Brahman literature to designate heretics over the centuries: nāstika, asura and pāsand da. Examples show how these ideasdrawn mainly from Puranic and Sanskrit epic narratives-are deployed in specific circumstances, and illustrate how they have been used by some Buddhist authors.

Key words: Rg veda; Vedas; Hinduism; Sanskrit epics; Mahābhārata.

Antes de abordar el tema de la ortodoxia y las herejías en el hinduismo es importante hacer algunas aclaraciones. En primer

Recepción: 31 de octubre de 2017. / Aceptación: 24 de mayo de 2018.

* Universidad de California, Berkeley, reimann@berkeley.edu

${ }^{1}$ Una versión temprana de este artículo fue presentada en el V Coloquio Internacional Religión y Símbolo: "Ortodoxia, heterodoxia y herejías", Ciudad de México, 15-17 de agosto de 2012. 
lugar, la definición de hinduismo es un tema controvertido. Lo más preciso sería hablar de un término de aplicación amplia que abarca una serie de tradiciones - o religiones- del sur de Asia. No se trata de una agrupación amorfa de tradiciones, ya que hay elementos que la mayor parte de ellas comparten, pero definirlo se ha convertido hoy en tema de discusión entre especialistas.

A diferencia de las tres religiones llamadas abrahámicas -judaísmo, cristianismo e islam-, el hinduismo no tiene un libro único o principal considerado como texto sagrado. Si bien en las tres "religiones del libro" la Biblia es el texto de referencia inicial, en el hinduismo hay varios textos que son considerados esenciales por los adherentes de distintas tradiciones. La Bhagavad Gitâ, por ejemplo, tiene gran importancia en muchas comunidades religiosas, y es por eso que, durante el periodo colonial, fue visto como "la Biblia del hinduismo" cuando las autoridades buscaban un equivalente. Pero la Gìtā no tiene un estatus similar al de la Biblia, ya que hay tradiciones que les dan prioridad a otros textos.

El hinduismo tampoco tiene un dios único, sino que incluye tres grandes ramas sectarias -aunque tal vez sea más acertado llamarlas religiones-. Se trata del vaisnavismo o viṣnuismo, con Viṣnu como dios supremo; el śaivismo o śivaismo, para la que Śiva ocupa dicho lugar; $y$ las tradiciones que tienen una deidad femenina, Devī, como divinidad suprema. Además de estas tradiciones teístas, hay corrientes que creen en un principio supremo impersonal conocido como el brahman.

¿Cuáles son las implicaciones de esta situación en el tema que nos ocupa? Para hablar de herejía es necesario definir la ortodoxia, porque sólo por contraposición se puede determinarla. ¿Cuál es, entonces, la ortodoxia hinduista? La respuesta es que depende de las circunstancias y del periodo histórico del que se trate. El mejor punto de partida es la ortodoxia brahmánica, es decir, aquella que se deriva de las creencias y las prácticas de la clase social de los brahmanes, los sacerdotes tradicionales asociados originalmente a la religión védica, la cual dio lugar después al hinduismo. Desde esta perspectiva, la aceptación de los vedas como textos sagrados es esencial. Quien no los acepta se separa de la ortodoxia. También es importante admitir 
la división de la sociedad en cuatro clases sociales organizadas jerárquicamente, con los brahmanes a la cabeza.

Hay también otras ortodoxias, que dependen con frecuencia de la figura que se considere como el dios supremo, o del respeto o rechazo de ciertas prácticas y costumbres. Esto significa que es difícil o imposible establecer un centro de gravedad de la ortodoxia, un conjunto bien delimitado de creencias y prácticas de aplicación general en todas las tradiciones consideradas hinduistas. El problema se hace más agudo si tomamos en cuenta que, aun dentro de una misma tradición, algunos conceptos han cambiado a lo largo de los siglos y varían de secta en secta.

La segunda aclaración tiene que ver con la llamada "inclusividad" del hinduismo. En este artículo empleo el término para indicar que el hinduismo se ha desarrollado y ha crecido gracias a un proceso de incorporación y apropiación de diversas deidades. En lugar de rechazar a otros dioses y diosas, e incluso a grandes héroes, el hinduismo se los apropia y les concede un lugar en un gran esquema jerárquico en el que "mi" dios -o diosa- siempre se encuentra en la cima de la jerarquía, por encima de "tu" dios. Tu dios no es falso, pero se encuentra por debajo del mío. Este procedimiento lo emplean tanto los vaisnavas como los śaivas y los seguidores de la Diosa, aunque son los vaisnavas quienes lo han empleado con mayor eficacia. Gracias a este procedimiento, varios dioses y héroes fueron absorbidos por el vaisnavismo y considerados avatäras, descensos o manifestaciones del Visnu Supremo.

Esta técnica de apropiación también se manifiesta con gran frecuencia en relatos mitológicos cuando cierto dios o diosa enfrenta alguna crisis que no puede resolver por sí mismo y requiere de la ayuda de otra deidad. En narrativas vaiṣnavas, Śiva debe recurrir a Viṣnu para conseguir ayuda, pero en narrativas śaivas es al revés: Viṣnu es incapaz de resolver sus problemas serios sin la ayuda de Śiva.

La tercera aclaración es sobre el concepto de dharma. Para el hinduismo, la noción es fundamental. El campo semántico de la palabra es amplio, por eso los traductores de textos sánscritos la traducen de distintas maneras, dependiendo del contexto. Para nuestros propósitos, el dharma es la forma de vida correcta; 
la conducta adecuada de acuerdo con un conjunto de preceptos religiosos, morales y sociales. Define el comportamiento social, pero también permite alcanzar los más altos niveles de liberación espiritual. Estos preceptos dependen, claro está, de quién los promulgue. Por ejemplo, el dharma hinduista brahmánico difiere del dharma budista, si bien tienen algunos puntos en común, sobre todo en el área de la moral.

Este énfasis en la conducta ha permitido la sugerencia de que para el hinduismo lo importante no es tanto la ortodoxia como la ortopraxia. En otras palabras, se trata más de un comportamiento correcto -incluido el comportamiento ritualque de creencias correctas. Si bien hay algo de cierto en esta perspectiva, considero que la ortodoxia engloba ambas cosas, y no es necesario entrar en detalles al respecto.

Hay que recalcar que los conceptos de ortodoxia y herejía no son de fácil aplicación en el contexto indio. En este estudio considero que "herejía" se refiere a ideas, prácticas y creencias que desafían la "ortodoxia" brahmánica o se alejan de ella, aunque también me referiré a algunas variantes de lo que es la ortodoxia.

Para entender cómo se ha descrito a los herejes en diversos textos a lo largo de los siglos, revisaré con detenimiento el uso de tres términos: nāstika, asura y pāsaṇda.

\section{Los nāstikas}

Es importante señalar que en el texto sánscrito más antiguo, el $R g$ Veda ( $R V 2.12 .5,8.100 .3$; Van Nooten y Holland, 1994) (ca. 1200 a.e.c.), algunos poetas aluden a personas que afirman que el gran dios védico Indra no existe o "no es", na asti. Y en textos védicos posteriores al $R g$ Veda se expresan críticas en contra de quienes no hablan correctamente el idioma ritual, el sánscrito védico. El Śatapatha Brāhmaña (SB 3.2.1.23 en la recensión Mādhyandina; Eggeling, 1963; 4.2.1.18 en la recensión Kānnva; Swaminathan, 2000), por ejemplo, los llama asuras. En la literatura védica temprana y media, estos negadores y asuras podrían ser considerados los primeros herejes.

Es hacia finales del periodo védico -entre el 500 a.e.c y principios de la era común-cuando surgen en el horizonte 
grupos mejor delineados que no aceptan los vedas como textos sagrados, y es a partir de este momento cuando contamos con más información para hablar de herejías desde la perspectiva de los sacerdotes brahmanes.

En los siglos inmediatamente anteriores al comienzo de la era común, cobra gran importancia en la literatura la imagen del asceta que abandona la vida social para dedicarse a la búsqueda de la liberación espiritual. Estos ascetas renunciantes contrastan con los jefes de familia y los sacerdotes brahmánicos que viven en la sociedad. Si bien el incipiente hinduismo acabó por incorporar a los renunciantes a su esquema social, varios grupos de ascetas renunciantes y de grupos materialistas de la época rechazaban la autoridad de los vedas y la eficacia del ritual védico. Entre estos movimientos sobresalen los cārväkas (un movimiento materialista), los äjīuikas y, sobre todo, los jainistas y los budistas. A estos movimientos la ortodoxia brahmánica los calificaba con el término nāstika, que ha sido traducido por heterodoxo, ateo, negador $\mathrm{u}$ otros términos.

Literalmente, un nāstika es aquel que declara na asti, "no existe". Pero ¿qué es lo que no existe? ¿Qué es lo que niegan los nāstikas? Hemos visto el origen remoto de esta expresión en el Rg Veda, cuando algunos decían: Indra "no existe". A finales del periodo védico, sin embargo, la palabra nāstika adquirió un sentido más amplio. Con frecuencia se usa para designar a quienes niegan de manera general el carácter sagrado de los vedas y la eficacia del ritual védico, pero también se aplica a quienes no reconocen la existencia de un dios creador - un dios personal-, y a los materialistas, que niegan que haya otro mundo más allá de éste.

En contraposición a los que dicen que no hay, na asti, se encuentran los que afirman que sí hay, asti. Estos ästikas aceptan la ortodoxia brahmánica, y para ellos el ritual védico es plenamente eficaz y hasta necesario. Queda así delimitado el contraste entre nāstikas y āstikas, los herejes y los ortodoxos, o, para expresarlo más literalmente, quienes niegan y quienes afirman, como lo sugiere Nicholson (2010, p. 179).

No hay duda de que la creciente importancia e influencia de estos movimientos nāstikas que no aceptaban la eficacia del 
ritual védico obligó a la tradición brahmánica a definirse mejor, y a defenderse ante la acusación de que el ritual no producía resultados. Si la acción ritual, el karman ritual, no produce frutos, la función especializada de los sacerdotes se vuelve irrelevante. Y si la función ritual de los brahmanes pierde importancia, toda la estructura social basada en las cuatro clases sociales encabezadas por ellos se viene abajo. Como parte de la reacción brahmánica a estas críticas surgió una escuela filosófica, la mìmámsā, dedicada a defender la eficacia de la acción ritual. ${ }^{2}$ Pero la mìmàmsà no sólo defiende la eficacia del ritual, sino que va más allá y asevera que los vedas son textos revelados y eternos, sin autor humano, algo que no afirmaban los textos védicos (Bronkhorst, 2001, p. 84). La defensa de los vedas ante los negadores nāstikas la vemos en mucha de la literatura brahmánica de comienzos de la era común, y toma varias formas.

En el Mahābhārata (Mbh 3.32.36-38), una de las dos grandes epopeyas sánscritas, el héroe Yudhișthira, alarmado ante los reclamos de su esposa Draupadī, la acusa de nāstikya, negación o herejía, y le dice que no hay que dudar ni de los frutos de la acción ritual ni de la participación divina en los acontecimientos humanos ni de la validez general del dharma. Yudhisthira increpa a Draupadí diciéndole que debe aceptar que todo ello existe, que sí lo "hay", asti, y que descarte su postura negadora de "no hay", su nästikya."

Dice Yudhișthira:

El que no se vea el resultado [de las acciones] no quiere decir que haya que dudar/desconfiar del dharma ni de las divinidades. Hay que celebrar el ritual védico (yajina) cuidadosamente, y hay que dar/regalar sin resentimiento. ${ }^{4}$ El fruto de las acciones existe (asti). Éste es el dharma eterno [...] Por lo tanto, Draupadī (Krṣnāà), que tus dudas desaparezcan como la neblina. Acepta que todo [aquello] es (asti), y descarta tu postura negadora (nāstikya). ${ }^{5}$

${ }^{2}$ Me refiero a la llamada pūrva mìmāmsā y no a la uttara mìmāmsā, conocida comúnmente como vedānta.

${ }^{3} \mathrm{La}$ palabra nāstikatā, que aparece en algunas ocasiones en los textos, es sinónimo de nāstikya.

${ }^{4}$ En este contexto, dar se refiere a remunerar a los sacerdotes brahmanes.

${ }^{5}$ na phalädarśanād dharmạ śánkitavyo na devatäḥ/ yaștavyam cāpramattena

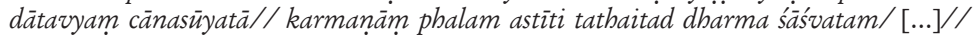


Las declaraciones de Yudhișthira amplían aún más el concepto de lo que debe ser aceptado y afirmado. Ya no se trata sólo de la eficacia del ritual, sino también de la validez de todo el dharma brahmánico, el cual ahora incluye una nueva clase de textos: los dharma śástras o libros sobre el dharma (Mbh 3.32.18 y todo el capítulo 3.32). En el Mānava Dharma Śästra (MDhS 2.10-11; Olivelle, 2005), un dharma śástra más o menos contemporáneo de nuestro fragmento del Mahābhärata, los dvijas, los dos veces nacidos que no aceptan sin cuestionamiento los textos brahmánicos tanto védicos (śruti) como posvédicos (smrti, los dharmas śástras), son considerados nāstikas y denigradores de los vedas.

En el Rāmāyaṇa (Ra 2.100.15-16) -la otra epopeya sánscrita- vemos un ejemplo de una postura negadora materialista cuando Rāma, el protagonista, instruye a su hermano Bharata sobre cómo ser un buen rey durante su ausencia. En medio de las instrucciones de Rāma, un brahmán llamado Jābāli le presenta a Bharata un punto de vista materialista, aseverando que los autores de los textos que prescriben donaciones, rituales y ascetismo para los brahmanes fueron compuestos para que los brahmanes contaran con ingresos garantizados. Jābāli declara que "no existe", na asti, un más allá después de la muerte. Rāma, como era de esperarse, refuta sus argumentos.

El Mahābhārata $(3.198 .66,12.15 .33$ y 12.309 .15$)$ y el $R \bar{a}$ māyana (2.61.22) también hablan de los nāstikas como quienes transgreden los límites, la frontera (maryàda) de la conducta aceptable. El rey los debe controlar por medio del castigo. $\mathrm{Y}$ en ambos textos la negación, el nästikya, se cuenta entre los defectos que los monarcas deben evitar (Mbh 2.5.96 y Ra 2.94.56). Un reino ideal no tiene nāstikas. Así pues, según el Ràmāyana (1.6.14), cuando Daśaratha, el padre de Rāma, era rey, no había nāstikas en el reino. Según Vyāsa, el supuesto

tasmāt te saṃsaya kẹsne nīhāra iva naśyatu/ vyavasya sarvam astīti nāstikyam bhāvam utsrja//. Todas las referencias del Măbābhärata y el Rāmāyana son a sus respectivas ediciones críticas, la de Sukthankar y Belvalkar (1933-1959) para el Mahäbharata, y la de Bhatt y Shah (1960-1975) para el Rāmāyana. Versión electrónica del Mahābhārata: John. D. Smith (revisión de la de Muneo Tokunaga), http://bombay.indology.info/ mahabharata/statement.html 
autor del Mahābhārata, el peor defecto de los nāstikas es que son hipócritas y falsos (Mbb 12.36.43).

Al terminar la gran batalla del Mahābhārata, cuando Yudhișthira y sus hermanos finalmente pueden celebrar su victoria, Yudhisthira - agobiado por el sentimiento de culpa tras haber matado a tantos parientes suyos- decide retirarse del mundo y no ser coronado como le corresponde. Sus hermanos, y el mismo Vyāsa, insisten en que debe asumir su responsabilidad de rey porque hacerlo es actuar conforme a lo indicado en los vedas, vedaniścaya (Mbb 12.14.1). No hacerlo constituiría una negación, nāstikya (Mbb 12.12.25). Así es como Yudhisthira, quien antes había acusado a Draupadī de esgrimir argumentos de los nāstikas, ahora es señalado por lo mismo por sus hermanos. Tras una larga discusión, Yudhișthira finalmente acepta asumir el trono y gobernar de acuerdo con el dharma brahmánico.

A principios de la era común algunos brahmanes se sentían tan amenazados por la difusión de las ideas de los nāstikas que temían que tal difusión causara el colapso total de su sistema social, ritual y de creencias. Lo expresaron declarando que, al final del Kali Yuga - la última y peor era según el sistema hinduista de eras del mundo-, los hombres fácilmente se convertirían en nāstikas (Mbb 3.188.22). Tales descripciones del final del Kali Yuga sin duda eran un reflejo de la manera en que estos autores vivenciaban su propia situación. La teoría de los yugas surgió en este contexto, y se habría de convertir en una de las piedras angulares del hinduismo.

Visto lo anterior, no es difícil adivinar qué les espera a los $n \overline{a s t i k a s}$ cuando dejan este mundo. No pueden ir al cielo ( $M b h$ 3.247.2-3) y están en la lista de quienes van al infierno $(R a$ 4.17.32).

\section{Los asuras}

Hemos visto quiénes son los nāstikas - los negadores- como herejes. Pero otro término común que se ha empleado para designar a los detractores de posturas consideradas correctas es asura, que se remonta al $R g$ Veda. En el $R g$ Veda, asura 
generalmente es un calificativo positivo. Sin duda significaba alguien poderoso o importante, y en varios himnos del $R g$ Veda se emplea para denominar a dioses como Varuna (2.28.7, 5.85.5), Rudra (2.33.9) y Soma (9.74.7). Sin embargo, con el paso del tiempo asura se convirtió en la designación de los antidioses - los demonios-, los cuales luchan constantemente por el control del mundo contra los dioses, los devas. ${ }^{6}$ En la literatura védica media - en los textos brāhmanas- encontramos narraciones de combates entre los devas y los asuras, y su lucha constituye el tema central de muchas narraciones mitológicas en las epopeyas, en los purānas y en otros textos posvédicos. $\mathrm{Si}$ bien generalmente es en narrativas mitológicas donde se habla de los asuras, el término asura y el adjetivo derivado de él, āsura, "asúrico", también se han utilizado para designar a los herejes.

La Chāndogya Upanișad (ChU 8.7-12; Olivelle, 1998), un texto védico tardío, cuenta que en una ocasión tanto los devas como los asuras se enteraron de que Prajāpati, el dios creador védico, afirmaba que era necesario conocer el verdadero àtman, el Ser interior de cada individuo. Al oír esto, ambos grupos mandaron a un representante a fin de que aprendiera de Prajāpati la doctrina del àtman. Los devas enviaron a Indra, el gran dios védico, y los asuras mandaron a Virocana. Cuando Prajāpati les explicó que el àtman equivalía al cuerpo físico, Virocana partió satisfecho y les transmitió esta doctrina errónea a los asuras. Indra, en cambio, regresó ante Prajāpati convencido de que esa no podía ser la verdadera enseñanza sobre el àtman. Prajāpati lo recibió nuevamente y, después de una estancia de varios años, le enseñó la verdadera doctrina: el cuerpo físico es mortal, mientras que el àtman es inmortal. La upanişad explica que, debido a que los asuras se contentaron con la enseñanza incorrecta, cuando alguien no celebra el sacrificio ritual, no tiene fe y no da regalos (a los brahmanes), tal persona es considerada un asura (ChU 8.8.5).

Esta breve narración ilustra muy bien cómo, desde la perspectiva de las upaniṣads, lo más importante es conocer el ātman,

${ }^{6}$ Otros dos términos comunes para referirse a los demonios son daitya (hijo de Diti) y dānava (hijo de Danu). 
el Ser interior. Las upanisads afirman la importancia del ritual védico, pero lo interpretan simbólicamente y consideran que el ascetismo y el conocimiento del àtman constituyen el camino superior, mientras que la práctica de los rituales védicos es el camino inferior. Nuestra breve historia también demuestra que quienes no entienden la verdad del ätman trascendente son como los asuras, los demonios. Son herejes.

En otra upanisad, la Maitrāyaniya (MU 7.10, texto en Van Buitenen, 1962; traducción al español en González Reimann, 1992), encontramos una historia similar. Los devas y los asuras se presentaron ante Brahman (en lugar de Prajāpati) a fin de recibir enseñanzas sobre el àtman. Brahman detectó que los asuras tenían malas intenciones y decidió enseñarles una doctrina errónea, gracias a la cual viven confundidos y aceptan lo falso como verdadero. La upanisad declara enfáticamente que lo que describen los vedas es la verdad, y que ningún sacerdote brahmán debe estudiar ideas que no sean védicas. La Maitrāyanīya también explica que el dios védico Bṛhaspati se convirtió en Śukra -el preceptor de los demonios- y creó la falsa doctrina de que no existe el ätman para destruir a los asuras y defender a Indra. La mención de la doctrina que niega la existencia del ätman es, sin duda, una referencia al budismo. Los asuras, continúa la upanișad, consideran que los vedas son un dharma de tipo himsaka, es decir un dharma que lesiona y causa daño, himsā (MÜ 7.9). Ésta es una alusión clara a la práctica del sacrifico ritual de animales en la tradición védica. Los jainistas y los budistas criticaban tal práctica, y aquí la upanisad responde a dichas críticas y los califica de asuras.

El budismo se convirtió en blanco importante de la ortodoxia brahmánica desde comienzos de la era común. La idea de que el dios védico Bṛhaspati se había convertido en Śukra para confundir a los asuras pronto fue adoptada por la tradición vaisnava, y se le aplicó directamente al budismo. La creciente importancia del budismo y la necesidad de aceptarlo como una realidad social hicieron que la tradición brahmánica lo explicara por medio de una hábil estratagema. El dios Viṣnu (no Bṛhaspati) nació como el Buda (en lugar de Śukra) para confundir a los asuras y llevarlos por el camino equivocado con sus enseñanzas no védicas. El Buda se convierte así en uno de 
los avatāras de Viṣnu, pero es un avatāra negativo que tiene la misión de descarriar y eliminar a los asuras.

En un pasaje tardío interpolado en algunas versiones del Mahābhārata (12, apéndice 31, líneas 1-7), Viṣnu anuncia su descenso como Buda con estas palabras:

Cuando comience el Kali Yuga me sentaré bajo el árbol rājataru y hablaré en la corte de reyes dhármicos en el idioma de Māgadha. Como Buda, hijo de Śuddhodana, con vestimenta roja, con [la cabeza] afeitada y con dientes blancos, confundiré a la humanidad. Cuando me convierta en el Buda, los śúdras ${ }^{7}$ disfrutarán [de los beneficios] de las ceremonias para los ancestros. Todos los hombres se vestirán de rojo. Los brahmanes no estudiarán [los vedas] y no mantendrán el fuego [ritual]. ${ }^{8}$

En siglos posteriores, cuando la influencia del budismo había disminuido drásticamente en el subcontinente y la nueva ortodoxia brahmánica posvédica se había sumado al rechazo del sacrificio ritual de animales, la imagen de Buda pierde su carácter negativo y es considerado con frecuencia como un avatāra compasivo que criticó el sacrificio de animales en las prácticas rituales. El conocido poeta vaisnava Jayadeva (siglo 12), por ejemplo, en su Gita Govinda ( $\dot{G} G$ 1.13; texto y trad. en Siegel, 1978) se refiere a Buda como el de corazón compasivo, sadayabrdaya.

La Bhagavad Gitā (BhG 16.4-16; Van Buitenen, 1981) ofrece una buena ilustración del uso del término asura, y especialmente del adjetivo "asúrico", para designar a los herejes. Haciendo eco de lo expresado en la Chāndogya Upanisad, Krșna explica que en este mundo hay dos tipos de seres: los de naturaleza divina (daiva) y los de naturaleza asúrica (āsura). Los asúricos - digamos los demoniacos- piensan que el mundo no tiene ni realidad ni fundamento ni señor/dios (iśvvara). Siguen doctrinas falsas y se dejan llevar por el egoísmo y por sus deseos. Se van al infierno.

${ }^{7}$ Los śúdras son los sirvientes. Se encuentran en el nivel más bajo del sistema de cuatro clases sociales, los varnas.

${ }^{8}$ tatạ̣ kaliyugasyādau b̆hūtvā rājatarum śritah/bhāsayā māgadhenaiva dharmarājagrhe vadan/ kāsāyavastrasamvitto munditah śukladantavān/ śuddhodanasuto buddhomohayișāmi mānavān/ śüdrāh śrāddihesu bhojyante mayi buddhatvam āgate/

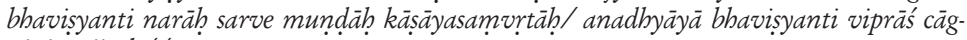
nivivarjitāhl//. 
Pero hay algo más en la narrativa de la Gìtā que es conveniente señalar. Así como en las upanisads la "ortodoxia" ya no sólo incluía la importancia del ritual védico, sino también su explicación simbólica - la cual gira en torno al concepto del ātman como verdad suprema-, en la Gìtā presenciamos otro desplazamiento del centro de gravedad de esta ortodoxia. Krṣna, al igual que las upanișads, considera relevante la aceptación de los vedas, pero en la Gìtā el respeto a los vedas ya no es el punto central. En la Gìtā, Krṣna mismo se convierte en el centro de atención, él es el dios supremo, y seguirlo a él es el camino superior. Sólo quienes recurren a él pueden traspasar la percepción errónea del mundo. Los ilusos que no recurren a él caen en un estado asúrico.

Dice Krṣna: "Los malhechores y los que están confundidos no acuden a mí, son lo peor entre los hombres. La ilusión $(m \bar{a} y \bar{a})$ les quita el conocimiento y viven en un estado asúrico" (BhG 7.15). ${ }^{9}$

A quienes son egoístas, orgullosos, violentos y lo odian, Krṣna los hace reencarnar como asuras, condición desde la cual no pueden alcanzarlo porque siguen un camino inferior $(B h G$ 16.18-20). Según esta narrativa, los herejes son aquellos que no aceptan que Kṛnna es el origen y el fin de todo, y que sólo a través de él se puede alcanzar la verdadera liberación. En una conocida declaración, Krṇna afirma de manera contundente: "Abandona todos los dharmas y acude sólo a mí por protección. Yo te liberaré de todo mal, no te aflijas" (BhG 18.66). ${ }^{10}$

\section{Los pāsaṇdas}

El tercer término que debemos analizar al hablar de herejía desde el punto de vista del hinduismo brahmánico es pāsaṇda. ${ }^{11}$

${ }^{9}$ na mām duskrtino müḍhāh prapadyante narādhamāḥ/ māyayāpahrtajñānā āsuram bhāvam àśritǟ

${ }^{10}$ sarvadharmān parityajya mām ekam śaraṇam vraja / ahaṃ tvā sarvapāpebhyo moksayișyami má śucaḥ//. En este verso, los dharmas seguramente son los diversos senderos posibles para alcanzar la liberación, el mokșa. Así, Kṛ̣nā niega la eficacia de cualquier otro sendero, como el budismo, que no dependa de él. Véase González Reimann, 2017, pp. 53-54.

${ }^{11} \mathrm{O}$ passandin. Algunos textos usan la variante päkhanda. 
En contraste con los nāstikas y los asuras, los päsandas son una categoría difusa y no muy bien definida. En las inscripciones del rey budista Aśoka, que datan del siglo III a.e.c., aparecen los términos pāsam da, pásam da y otras variantes, dependiendo del dialecto prácrito empleado en las inscripciones (Block, 1950). En las declaraciones de Aśoka, los pāsandas parecen ser diversos grupos de ascetas que el rey quiere que habiten en cualquier parte del reino y gocen de libertad para practicar sus disciplinas o seguir sus propias ideas. Aśoka menciona a los brahmanes y a los śramanas (samanas, en lengua pali), una palabra que generalmente se refiere a diferentes comunidades de ascetas, como los budistas, los jainistas y los ajižizas, así como a grupos materialistas (Jaini, 1970). Pero Aśoka menciona aquí también a los pāsañdas. No queda claro, entonces, cuál es la diferencia entre los śramanas y los päsandas en las inscripciones, pero no parece haber duda de que los pasasandas son grupos sectarios que siguen filosofías o reglas de conducta específicas. Los traductores de las inscripciones generalmente traducen passanda por secta, aunque Schneider (1978) lo traduce como "grupo religioso", religionsgemeinschaft.

En la literatura brahmánica, por otra parte, el contexto en que se habla de los passandas indica que se trata de individuos o grupos que no respetan ni los vedas ni el ritual védico ni, por extensión, el dharma de los brahmanes. En un pasaje del Mahäbhärata (3.186.43 y 3.189.9) que habla de las atrocidades del final del Kali Yuga, el poeta se queja de que, en esos tiempos terribles, los ashrams caerán en manos de los päsandas. ${ }^{12}$ En otras secciones de la epopeya se habla de ellos como personas que corrompen (a los seguidores de los vedas, se entiende), y al igual que en el caso de los nāstikas, los päsandas aparecen en una lista de quienes se van al infierno (Mbb 13.24.67). ${ }^{13}$ En un pasaje interpolado en un manuscrito del Mabābhārata (línea 4, insertada después de 12.49.62. ${ }^{14}$ Véase también la línea 24 después

${ }^{12}$ Un ashram (ā́rama) es un lugar alejado de zonas pobladas donde vive un asceta con sus discípulos.

13 "Los pāsaṇdas corrompen [...] se van al infierno (niraya)", pāṣanḍ̄ dūsakāás... nirayagaminah.

14 "Los brahmanes dejan su propio dharma y buscan refugio con los pāsandas",

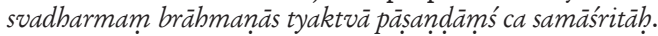


de 12.221.57, apéndice 1, núm. 22) se habla de brahmanes que abandonan su dharma y se convierten en pāsāndas.

La imagen antivédica y antibrahmánica de los pāsandas continúa en los purānas y otros textos posvédicos. El Viṣnu Purāna (VP 6.1.44-49; texto en Pathak, 1997-1999 y en Sharma, 1985; trad. en Wilson, 1972), por ejemplo, declara que la intensidad del Kali Yuga aumenta en la medida en que se difunden las doctrinas de los pāsandas y disminuye el respeto por los vedas. El Matsya Purāna (MP 57.6, 69.34 y 99.14, texto en la ed. de Meharchand Lachhmandas, 1984; trad. en A Taluqdar of Oudh, 1980) afirma que no hay que asociarse con los pāsandas. Incluso los śúdras, la clase social más baja, deben evitar hablar con los passandas. Este purāna repite lo dicho por el Mahäbhärata y otros textos, en el sentido de que en el Kali Yuga -y especialmente al final- todo tipo de personas y grupos indeseables cobrarán importancia. La lista de los indeseables incluye a los kāsāyins, monjes budistas, y a los kāpālikas, una secta śaiva (MP 144.40-41). El Vāyu Purāna (VaP 1.58.6465; texto en Chaturveda, 1983; trad. Tagare, 1987-1988) tiene una lista similar, pero agrega a los nirgranthas y a los jainistas. Según el Matsya (144.40-41), Kalkin, el avatāra futuro que rescatará a la sociedad brahmánica al final del Kali Yuga, destruirá a los päsandas.

Un pasaje interpolado en algunas versiones del Mahäbhārata (12, apéndice 31, líneas 18-21) lo expresa así: "Al final del Kali Yuga [naceré] como Kalkin, un brahmán café amarillento, hijo de Viṣnuyaśas, sacerdote de Yājñavalkya. Con la ayuda de mis seguidores brahmanes aniquilaré por completo a los mlecchas [extranjeros/bárbaros] y a los päsandas". ${ }^{15}$

El Mānava Dharma Śästra (9.225, también en Mbb 12.138. 40) declara que los passandas están entre los indeseables que el rey debe desterrar. Y el $\dot{B} \dot{h} \overline{a g a v a t a}$ Purāna (BhP 11.14.8), un texto muy influyente en el vaisnavismo del norte de India, reconoce que hay distintas interpretaciones de la tradición védica debido a la diversidad de linajes (parampara), y como conse-

${ }^{15}$ tatạ̣ kaliyugasyānte brāhmaṇo haripingalaḅ/kalkir viṣnuyaśạ̣putro yājñavalk-

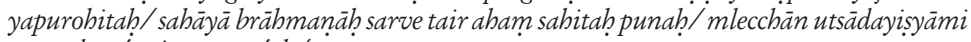
pāsaṇ̂āịś caiva sarvaśạ̣/. 
cuencia de variantes en la naturaleza de los individuos, pero menciona a los passandas como una categoría aparte. Confirma así el carácter anti o extra védico de los pāsandas (Bhāgavata Purāna, 2006).

La palabra pāsanda se ha traducido de diversas maneras, con términos como hipócrita, hereje o impostor.

\section{Herejes y más herejes}

Hemos visto que los textos brahmánicos emplean nāstika, asura y pāsanda para designar a los herejes. Aunque las primeras dos palabras, nāstika y asura, tienen un significado más o menos delimitado - los nāstikas como negadores y los asuras como demonios-, pāsanda parece ser un término más genérico. Es evidente que en la literatura brahmánica la característica definitoria de todos es su aversión a la tradición védica y al estatus privilegiado de los vedas y el dharma brahmánico. Sin embargo, hay que señalar que estas palabras, sobre todo nāstika y pāsanda, también las usan autores budistas para referirse a quienes ellos consideran herejes. Nos encontramos con un ejemplo en el Lànkāvatāra Sütra (LS 2.36; Suzuki, 1966), texto budista que habla de pāsandas al referirse a individuos considerados como herejes desde la óptica budista.

Más allá de la defensa de los vedas y del dharma brahmánico en general, la literatura puránica a veces critica y ataca a ciertas sectas o corrientes específicas. No es raro, por ejemplo, leer ataques a sectas śaivas o vaiṣnavas. Acabamos de ver ejemplos del Matsya Purāna y del Vàyu Purāna que rechazan a los budistas, los jainistas y a la secta śaiva de los kāpālikas. Pero otros purānas incluyen a más grupos considerados heréticos. El Kürma Purāna (KP2.16.15, 2.21.34, 2.26.68; Gupta, 1972, edición crítica, texto y trad.) agrega a los pāñcarātras, una secta vaiṣnava; los vāmācāras, una designación que se refiere a practicantes de tantrismo; los pāśupatas, otra secta śaiva, y los haitukas, racionalistas.

La versión más extrema del rechazo a herejías tal vez se encuentre en un purāna vaisnava, el Padma Purāna (PP 6.235236; González Reimann, 2002, pp. 194-195; texto del pasaje 
completo en Shastri, 1984, vol. 3), en una sección tardía que da una larga lista de concepciones y grupos considerados por el autor como negativos. El texto menciona específicamente a los cārvākas (materialistas) y a tradiciones filosóficas y religiosas reconocidas como el vaiśesika, el nyyāya, la mìmāmsāa, el sāmkhya y el vedānta. Además, el Padma clasifica a los purānas tomando en cuenta si conducen a la liberación, al cielo o al infierno. Como es de esperarse, todos los textos que conducen a la liberación son vaisnavas.

Esta sección también incluye un ataque al famoso filósofo śaiva Śamkara, el principal representante de la escuela vedānta no dualista, el advaita vedānta. Retomando la crítica del budismo que aparece en textos vaiṣnavas — según la cual Vị̣nu encarnó como Buda para confundir a los demonios-, el texto recicla el argumento y lo extiende para aplicárselo también a Śamkara, pero con una ligera variante. Según el purāna, el dios Šiva (ya no Viṣnu) nació como Śamkara a fin de promulgar la falsa teoría del àdvaita vedānta.

Śiva se lo explica a su esposa Pārvatī:

Con el propósito de destruir a los demonios (daityas), Viṣnu tomó la forma del Buda y enseñó la falsa doctrina budista [que siguen] quienes andan desnudos, los que se visten de color oscuro y otros.

La doctrina de la ilusión (māyāvāda) es falsa, es budismo disfrazado. Yo la proclamé en Kali (Yuga) bajo la forma de un brahmán, joh, diosa! (PP 6.236.6-7; González Reimann, 2002, p. 176). ${ }^{16}$

La doctrina de la ilusión es el advaita vedānta, y el brahmán que la promulgó es Śamkara.

La acusación de que la doctrina del advaita vedānta se asemeja demasiado al budismo y que, por lo tanto, es budismo disfrazado, la lanzó Madhva (siglo XIII), el principal exponente de otra escuela del vedānta, el vedānta dualista o dvaita vedānta. Los seguidores de Madhva habrían de acusar a Śạkara de ser un budista camuflado (pracchannabauddha) y de ser perverso (pāpa), al considerar que sus ideas eran una perversión de los

${ }^{16}$ daityānām nāśanārthāya viṣnunā buddharupiṇā / bauddhaśāstram asat proktam nagnanilapațädikam // māyāvädam asac chästram pracchannam baudha [sic] ucyate/ mayaiva kathitạ̣ devi kalau brāhmanarūpiṇā //. 
vedas. Hay un ejemplo de esto en el poema hagiográfico Sumadhva Vijaya de Nārāyaṇa Paṇịtācarya (1.48, 51; Rau, 1983). Aquí entramos en el terreno de las críticas sectarias en las ramas de una misma escuela -el vedānta-, y esto ilustra lo anotado al principio, en el sentido de que es difícil ubicar el centro de gravedad exacto de la ortodoxia del hinduismo, sobre todo en la medida en que el tiempo avanza y proliferan distintas ramas y subramas de una misma escuela.

\section{Consideraciones finales}

Me he concentrado en lo que constituye una herejía desde la perspectiva brahmánica tradicional, y para ello he analizado tres términos empleados para designar a los herejes: nāstika, asura y päsanda. Desde la perspectiva de los textos brahmánicos, el principal elemento del pensamiento y el comportamiento heréticos es el rechazo de la autoridad de los vedas y del dharma brahmánico. Sin embargo, hemos visto cómo, aun en el marco del respeto a los vedas, hay distintas tradiciones que se centran en diferentes elementos. Para las upanișads, lo principal es el conocimiento del Ser, el àtman, mientras que en la Bhagavad Gìtā el centro lo constituye el reconocimiento de que Krșna es el dios supremo. Y en otros textos ya no son sólo los vedas sino también los textos brahmánicos posvédicos los que deben aceptarse como autorizados. Se podrían establecer otros criterios para definir el comportamiento herético; el que he presentado es el más generalizado en la literatura brahmánica y, sin duda, el más importante, pero no el único en las tradiciones hinduistas. Ampliando el espectro, podríamos decir que hay tantas herejías como hay doctrinas. Y sabemos que hay una gran variedad de doctrinas en las tradiciones que conforman el hinduismo.

\section{Abreviaturas}

BhG: Bhagavad Gìtā

BhP: Bhägavata Purāna 
ChU: Chāndogya Upaniṣad

GG: Gìta Govinda

KP: Kürma Purāna

LS: $\quad$ Lañkāvatāra Sūtra

Mbb: Mahābhārata

MDhs: Mānava Dharma Śāstra

MP: $\quad$ Matsya Purāna

MU: Maitrāyañìa Upanisad

PP: Padma Purāna

Ra: Rāmāyana

$R V: \quad R g V e d a$

SB: $\quad$ Satapatha Brābmana

VaP: Vāyu Purāna

VP: Viṣnu Purāna

Dirección institucional del autor:

Department of South and Southeast Asian Studies

University of California, Berkeley

233 Drinelle Hall

Berkeley, CA 94720-2520, U.S.A.

\section{Referencias}

A Taluqdar of Oudh (Trad.). (1980 [1916]). The Matsya Puranam. Nueva Delhi: Munshiram Manoharlal.

Bhāgavata Purāna (2006). Recuperado de http://gretil.sub.uni-goettingen.de/gretil/1_sanskr/3_purana/bhagp/bhp1-12u.htm

Bнatт, G. H. y Shah, Ü. P. (Eds.). (1960-1975). The Vālmīki Rāmāyana: Critical edition (7 vols.). Baroda: Oriental Institute.

Block, J. (Trad.). (1950). Les inscriptions d'Asoka. París: Les Belles Lettres.

BRONKHORST, J. (2001). The origin of Mīmāmsāa as a school of thought: A hypothesis. En K. Karttunen y P. Koskikallio (Eds.), Vidyārnavavandanam: Essays in honour of Asko Parpola (pp. 83-103). Helsinki: Finnish Oriental Society.

Chaturveda, V. (Ed.). (1983). Śrì Vāyumahāpurānam. Delhi: Nag Publishers.

Eggeling, J. (Trad.). (1963 [1882-1900]). The Śatapatha-brâbmana: according to the Mâdhyandina School. Delhi: Motilal Banarsidass. 
González R., L. (Introd., trad. y notas). (1992). La Maitrāyaṇīya Upanisad. México: El Colegio de México.

GONZÁLEZ R., L. (2002). The Mahābhärata and the Yugas: India's great epic poem and the Hindu system of world ages. Nueva York, NY: Peter Lang.

GonZÁlez R., L. (2017). Kalpas, yugas y la Bhagavadgìtā como texto para promover la supremacía de Krṣna. En O. Figueroa (Ed.), La Bhagavad-gìtā: el clásico de la literatura sánscrita y su recepción (pp. 43-58). México: Universidad Nacional Autónoma de México.

GuptA, A. S. (Ed.). (1972). The Kürma Purāna, with English translation. (Trads. Bh. Ahibhushan y M. Satkari). Varanasi: All-India Kashi Raj Trust.

JAINI, P. S. (1970). Śramanas: Their conflict with Brāhmanical society. En J. Elder (Ed.), Chapters in Indian civilization (vol. 1, pp. 4181). Dubuque, IA: Kendall Hunt.

Matsyamahāpurānam (1984). Nueva Delhi: Meharchand Lachhmandas.

Nicholson, A. J. (2010). Unifying Hinduism: Philosophy and identity in Indian intellectual history. Nueva York, NY: Columbia University Press.

Olivelle, P. (Trad.). (1998). The early Upanisads: Annotated text and translation. Nueva York, NY: Oxford University Press.

Olivelle, P. (Ed. y trad.). (2005). Manu's code of law: A critical edition and translation of the Mānava-Dharmaśástra. Nueva York, NY: Oxford University Press.

PathaK, M. M. (1997-1999). The critical edition of the Viṣnupurānam. Recuperado de http://gretil.sub.uni-goettingen.de/gretil/1_sans$\mathrm{kr} / 3$ purana/visnup u.htm

Rau, V. (Ed. y trad.). (1983). Nārāyaṇa Panditācarya's Sumadbva Vijaya. Viśākhapatnam: Śrimadānanda Tirtha Publications.

SChNeIDER, U. (1978). Die Grossen Felsen-Edikte Aśokas: Kritische ausgabe, übersetzung und analise der texte. Wiesbaden: Harrasowitz.

Sharma, R. (Ed.). (1985). Śrī Viṣnumahāpurāṇam. Delhi: Nag Publishers.

Shastri, C. (Ed.). (1984). Śrī Padmamahāpurānam (vol. 3). Delhi: Nag Publishers.

SIEGEL, L. (1978). Sacred and profane dimensions of love in Indian traditions as exemplified in the Gitagovinda of Jayadeva. Delhi: Oxford University Press.

SukThankar, V. S. y Belvalkar, S. K. (Eds.). (1933-1959). The Mahā- 
bhärata: For the first time critically edited (19 vols.). Poona: Bhandarkar Oriental Research Institute.

Suzuki, D. T. (Trad.). (1966). The Lànkāvatāra Sūtra: A Mahāyāna text translated for the first time from the original Sanskrit. Londres: Routledge \& Kegan Paul.

Swaminathan, C. R. (Ed. y trad.). (2000). Kānvaśatapathabrāhmanam (vol. 3). Nueva Delhi: Indira Gandhi National Centre for the Arts.

Tagare, G. V. (Trad.). (1987-1988). The Vāyu Purāna (2 vols.). Delhi: Motilal Banarsidass.

Van Buitenen, J. A. B. (Ed. y trad.). (1962). The Maitrāyaniya Upanisad: A critical essay, with text, translation, and commentary. La Haya: Mouton.

Van Buitenen, J. A. B. (Ed. y trad.). (1981). The Bhagavadgita in the Mahābhārata: Text and translation. Chicago, CHI: University of Chicago Press.

Van Nooten, B. y Holland, G. B. (Eds.). (1994). Rig Veda: A metrically restored text with an introduction and notes. Cambridge, MA: Harvard University Press.

Wilson, H. H. (Trad.). (1972 [1840]). The Vishnu Purāna: A system of Hindu mythology and tradition. Calcuta: Punthi Pustak. 